\title{
TRANSKRIPSI STRUKTUR PENYAJIAN LAKON RABINE PANJI PADA KELOMPOK WAYANG TOPENG TRADISI KEDUNGMONGGO MALANG
}

\author{
Endang Wara Suprihatin, Dyah Pratamawati, Tri Wahyuningtyas, dan Hartono
}

\author{
Jurusan Seni dan Desain Fakultas Sastra Universitas Negeri Malang
}

\begin{abstract}
Malang is popular with one of its traditional dance that is Malang Puppet Mask (Wayang Topeng Malang, shortened into WTM). WTM has several characteristics, they are: (1) retelling Panji stories; (2) all dancers wear puppet mask with its own characters; (3) puppet master is usually performed by male and is responsible to tell stories and narrate the dialogs; (4) the stage has its definite patterns and cannot be changed according to the puppet master's will. Panji's stories and narration are based on folk lore so that the form and the structure are based on the puppet master's memories, perception and variation, WTM artists, and the society. Sanggar Asmoro Bangun as one of WTM groups, located in Kedungmonggo village, Malang District, presents the dance into two versions, they are: (1) full duration to perform Rabine Panji (Panji's Marroage); and (2) short version in performing Rabine Panji. Both versions influence several aspects in performing the dances, such as, the structure, the time, the scenes and the music.
\end{abstract}

Keywords: the persentation structure, the movement techniques, malang mask dance drama

\begin{abstract}
Abstrak: Malang memiliki seni tradisional yang populer yaitu Wayang Topeng Malang. Ciri karateristik Wayang Topeng Malang adalah: (1) membawakan cerita Panji, (2) semua penari (anak wayang) memakai topeng tokoh yang sesuai dengan lakon yang dimainkan, (3) dhalang diperankan oleh laki-laki, dan bertugas sebagai pembawa ceritera dan melakukan dialog, (4) konsep pemanggungan mengikuti struktur yang sudah ditetapkan dan tidak bisa diubah sesuai dengan keinginan dhalang. Kelompok Sanggar Asmoro Bangun dusun Kedungmonggo Kabupaten Malang mengembangkan struktur penyajian lakon Rabine Panji dalam dua versi yaitu: (1) tata urutan penyajian lakon durasi penuh dan (2) tata urutan penyajian lakon durasi pendek/tidak penuh. Kedua versi penyajian tersebut berpengaruh terhadap struktur penyajian, waktu penyajian, pembagian adegan serta musik iringan tari yang dibawakan.
\end{abstract}

Kata kunci: struktur penyajian, teknik gerak, drama tari topeng malang

The Pigeaud dalam bukunya "Javaanse Volksvertoningen" mengatakan bahwa seni tradisional Wayang Topeng adalah seni pertunjukan yang sangat populer di Malang 
(Pramono, Sholeh dan, Supriyanto, 1997:6). Wayang Topeng merupakan pertunjukan tari topeng yang menampilkan sebuah dramatari dengan pelaku-pelaku yang bertopeng (Murgiyanto dan Munardi, 1980:7). Seni tradisional Wayang Topeng Malang pada dekade tahun 70 an pernah menjadi ikon kota Malang (Septivirawan, 2011). Karateristiknya: (1) membawakan cerita Panji, (2) semua anak wayang memakai topeng tokoh yang sesuai dengan lakon yang dimainkan, (3) dhalang diperankan oleh laki-laki, dan bertugas sebagai pembawa cerita dan melakukan dialog karena semua anak wayang/tokoh tidak melakukan dialog sendiri, kecuali tokoh Patrajaya yang menggunakan topeng hanya separuh wajah, (4) konsep pemanggungan mengikuti struktur yang sudah ditetapkan dan tidak bisa diubah sesuai dengan keinginan dhalang.

Dulu, Wayang Topeng Malang tersebar di wilayah Dampit, Precet, Wajak, Ngajum, Jatiguwi, Senggreng, Pucangsanga, Jabung dan Kedungmonggo. Namun, sekarang hanya tinggal 4 kelompok Wayang Topeng saja yang masih aktif dan 3 diantaranya mengalami penyusutan (Hidayat, 2008: 24-27). Saat ini, yang masih eksis adalah: (1) Perkumpulan Wayang Topeng Karya Bhakti dari Desa Jabung, diketuai oleh Parjo; (2) Perkumpulan Wayang Topeng Sri Marga Utama dari Desa Glagahdawa, Tumpang dipimpin oleh Rasimun (almarhum); (3) Perkumpulan Wayang Topeng Asmoro Bangun dari Desa Kedungmonggo, Pakisaji dipimpin oleh mbah Karimun (almarhum); (4) Perkumpulan Wayang Topeng Candrakirana dari Desa Jambuwer, Sumberpucung di pimpin oleh Bardjo Djiyono.

Wayang Topeng Malang, menyajikan ceritera Panji yang bersumber pada tradisi lisan sehingga bentuk dan struktur penyajian lakon sesuai dengan daya ingat dan variasi yang dilakukan dhalang. Perbedaan bentuk dan struktur penyajian serta variasi pementasan Wayang Topeng Malang dari masing-masing kelompok ini menjadi sangat variatif dan unik. Beberapa penelitian yang telah dilakukan terhadap seni pertunjukan Wayang Topeng Malang di antaranya adalah penelitian tentang: (1) Wayang Topeng Malang: Kajian Struktur Simbolik (Hidajat, 2005); (2) Makna 4 Tokoh Sentral Wayang Topeng Malang (Hidajat. 2000; (3) Pengembangan Model Pembelajaran Teilerin Multimedia Interactiv (TMI) Untuk Menunjang Pembelajaran Tari Daerah Malang (Rahayuningtyas, 2015); (4) Tari Topeng Bapang (Hidajat, 1996); Sampai dengan saat ini, penelitian tentang struktur penyajian Wayang Topeng dari setiap Sanggar dalam pertunjukan wayang topeng Malang belum pernah dilakukan.

Penelitian ini bertujuan mendiskripsikan struktur penyajian ceritera dan pengembangan teknik gerak pada lakon "Rabine Panji” di Sanggar Wayang Topeng Asmoro Bangun dusun Kedungmonggo. Ceritera ini ditetapkan sebagai subyek penelitian karena ceritera Rabine Panji dalam pertunjukan Wayang Topeng Malang tidak begitu populer dibanding dengan cerita-cerita lain, sehingga perlu diinventarisasi agar tidak punah.

Kesenian tradisional adalah kesenian yang diwariskan secara turun temurun dari satu generasi kepada generasi selanjutnya dan berlangsung dalam waktu lama serta seringkali bersifat anonim (Bastomi, 1988:14). Kesenian tradisional akan mati atau punah jika pandangan hidup serta nilai-nilai kehidupan masyarakat pendukungnya tergeser oleh nilainilai baru. Pergeseran nilai bisa terjadi apabila didesak oleh kesenian dari luar yang lebih kuat (Bastomi, 1988:16). Fungsi dan peranan kesenian tradisonal dapat berkembang menurut kebutuhannya, bukanlah sesuatu yang beku, dan dapat berkembang seiring dengan pertumbuhan adat budaya masyarakat pemiliknya. Kesenian tradisional dapat menjadi filter terhadap derasnya pengaruh kesenian yang datang dari luar (Rendra dalam Erneste P, 1983:45). Secara historis, terdapat konflik budaya nusantara: (1) budaya pedalaman dengan budaya pesisiran, (2) budaya keraton dengan budaya rakyat, dan (3) budaya santri dengan budaya 
abangan. Sejak itu pula kesenian tradisional sering disebut sebagai "seni adiluhung" yang merupakan jenis ungkapan seni yang mempunyai implikasi kepada perenungan dan memiliki nilai citra progresif dan bernilai tinggi (Yudistira, 2010).

Penelitian ini, tidak akan mempertentangkan konflik budaya tetapi menempatkan kesenian tradisional sebagai warisan leluhur di masa lampau yang patut dijaga dan diselamatkan dari kepunahan karena tergerus arus zaman. The Pigeaud dalam bukunya "Javaanse Volksvertoningen" (Pramono, 1997:6) mengatakan bahwa seni tradisional Wayang Topeng adalah seni pertunjukan yang sangat populer di Malang. Pementasan Wayang Topeng lazimnya dilaksanakan mulai pukul 20.00 sda pukul 05.00 (semalam suntuk). Perkumpulan Wayang Topeng di Dusun Kedungmonggo sudah cukup tua, kini beralih ke cucunya sebagai generasi ke lima. Wayang Topeng Malang Asmoro Bangun bersinar dan mencapai jaman keemasan pada masa awal 1970-an hingga 1990-an (Zuhri, 2009). Kenyataan ini kemudian menjadikan dusun Kedungmonggo menjadi wilayah unggulan Kabupaten Malang sehingga pihak Pemda memfasilitasi pembangunan transportasi untuk menuju dusun tersebut. Namun, kejayaan itu semakin surut.

\section{METODE}

Penelitian ini menggunakan pendekatan kualitatif dengan rancangan penelitian ethnochoreology/etnokoreologis. Fokus pada tari khas milik etnis Jawa Timur yang meliputi kesejarahan, antropologis dan sosiologis (Soedarsono, 1999:15). Penelitian ini mengkaji terhadap tindakan atau kegiatan seseorang atau beberapa orang yang berkenaan dengan penyajian lakon Rabine Panji versi kelompok Topeng Sanggar Asmoro Bangun. Lokasi penelitian kelompok Wayang Topeng Malang Sanggar Asmoro Bangun, dusun Kedungmonggo, Pakisaji, Malang. Dipilihnya kelompok topeng sebagai lokasi penelitian karena saat ini hanya kelompok itulah yang eksistensinya masih terjaga, dan pementasan lakon di sanggar tersebut sangat spesifik dibanding pementasan yang sama pada kelompok Wayang Topeng Malang yang lain. Penelitian ini termasuk studi kasus oleh karenanya sumber data tidak hanya mengandalkan satu sumber saja (Burns, 1994:321), tetapi dilakukan dengan menggali informasi dari wawancara mendalam dengan narasumber (Sudikan, 2001:106, Yuwana, 2001) peristiwa dan aktivitas, tempat atau lokasi, benda, beragam gambar dan rekaman, arsip gambar, foto atau benda peninggalan/artefak (Sutopo, 2002: 54). Dalam penelitian ini, sumber data berasal dari hasil wawancara dan studi dokumen.

\section{HASIL DAN PEMBAHASAN}

\section{Struktur Penyajian Lakon "Rabine Panji” Pada Sanggar Wayang Topeng Asmoro Bangun Dusun Kedungmonggo \\ Tata Urutan Penyajian Dalam Pementasan Seni Pertunjukan Gaya Malangan}

Berdasarkan analisis dokumen buku Topeng Malang, pertunjukan Wayang Topeng

Malang diawali alunan musik pembuka sebagaimana pernyataan berikut ini:

... sebagai pembuka diperdengarkan gendhing-gendhing Giro.... Setelah permainan gendhing itu berlangsung secukupnya...., mereka akan berhenti sejenak menunggu sampai suasana dirasakan siap. Kemudian diperdengarkan gendhing-gendhing Gagahan misalnya Gagahan Gunungsari (Murgiyanto dan Munardi 1980: 40-45).

Gendhing Giro adalah alunan musik yang berasal dari instrumen gamelan yang dibawakan sebagai musik penyambut tamu sekaligus sebagai suatu tanda bahwa di tempat 
tersebut ada pertunjukkan, sekaligus sebagai penanda bahwa pertunjukkan akan segera dimulai. Handoyo (wawancara tgl 24 Nopember 2013) mengatakan, " giro sebagai tanda dimulainya acara pertunjukan adalah ... saat di mana para niyaga/pengrawit membunyikan gendhing Giro sebagai pertanda akan dimulainya pertunjukan ". Sebagai pembuka pertunjukan, diawali dengan gendhing pambuka berlaras slendro sanga atau bisa juga gendhing laras pelog pathet barang yaitu gending Eling-eling.... Dilanjutkan dengan gending Krangean, laras pelog pathet barang. Giro yang terkenal di dalam pertunjukan wayang topeng (Murgiyanto dan Munardi, 1980:40). Setelah gendhing Giro selesai diperdengarkan dan penonton bersiap mengikuti pagelaran maka acara selanjutnya adalah sajian tari pembuka. Dalam pertunjukan Wayang Topeng Malang setelah gendhing Giro maka acara selanjutnya adalah tari pembukaan (Murgiyanto dan Munardi,1980:41). Sementara itu berdasarkan wawancara dengan Robby Hidajat (tgl 18 Nopember 2013) menyatakan bahwa: “...struktur repertoar Panji pada Wayang Topeng Kedungmonggo berbeda dengan struktur penyajian kelompok yang lain... salah satu yang dapat diperhatikan adalah diawali dengan tari pembuka yang disebut patih". Apa yang disampaikan oleh Robby Hidajat tersebut, senada dengan pernyataan Handoyo dalam wawancara (tgl 24 Nopember 2013) yaitu "...bahwa pembukaan pertunjukan Wayang Topeng di Kedungmonggo adalah sajian tari beskalan patih".

Dengan demikian, dapat disimpulkan sementara bahwa: (1) Tata urutan penyajian dalam pementasan seni pertunjukan gaya malangan mengikuti pola adanya penyajian gendhing Giro yang merupakan gendhing khas Malangan; (2) Gendhing Giro tersebut dimaksudkan sebagai penyambut tamu sekaligus sebagai penanda akan dimulainya pertunjukan.

\section{Tata Urutan Penyajian Lakon Rabine Panji Versi Sanggar Topeng Asmoro Bangun Kedungmonggo}

Pramono, Supriyanto dan Sholeh (1997: 57) menyatakan bahwa yang dipentaskan adalah lakon tentang: "(1) Panji reni, (2) Rabine panji, (3) Panji laras, (4) Sayembara sada lanang, (5) Geger gunung wilis, (6) Keong mas, (7) Mlati putih edan, (8) Walang sumirangwalangwati, (9) Badher bang sisik kencana, (10) kayu apyun". Menurut Wido dalam wawancara tanggal 18 Nopember 2013, "struktur penyajian berbeda beda, hal tersebut disebabkan oleh adanya cara pandang dan intepretasi yang tidak sama di antara seniman pelaku Topeng dan juga Dhalang". Sementara menurut Handoyo, pemimpin sanggar Topeng Asmoro Bangun Kedungmonggo dalam wawancara tanggal 24 Nopember 2013 menyatakan bahwa:

...tata urutan penyajian pertunjukan Wayang Topeng tergantung pada durasi waktu yang dipakai dalam pertunjukan...untuk pertunjukan penuh dimana waktunya semalam suntuk (jam 21.00 - 05.00) tata urutannya berbeda dengan penyajian dengan durasi waktu dua jam...

Dengan demikian, kesimpulan sementara adalah: (1) Lakon yang dibawakan dalam pertunjukan Wayang Topeng bervariasi; (2) Lakon tersebut bersifat cerita garis besar atau ceritera baku; (3) Waktu penyajiannya pun bervariasi

\section{Tata urutan penyajian lakon Rabine Panji dengan durasi penuh}

Tata urutan penyajian lakon Rabine Panji dengan durasi penuh dilaksanakan semalam suntuk, dari jam 21.00 sampai dengan jam 05.00. Dari analisis dokumen lakon Rabine Panji dalam buku Dramatari Wayang Topeng (Supriyono dan Sholeh, 1997: 60) dinyatakan bahwa cerita lengkap dari lakon Rabine Panji diawali dari jejer Raja Jenggala Manik sampai 
perhelatan Panji dan Sekartaji. Menurut Handoyo (wawancara tanggal 24 Nopember 2013) “... jika lakon tersebut dibawakan secara utuh dengan durasi waktu semalam suntuk yaitu pukul 21.00 sampai dengan 05.00 maka dapat dikatakan sebagai penyajian penuh...”.

Sementara itu, berdasarkan analisis dokumen yang ditulis oleh Murgiyanto dan Munardi (1980:24-25): “ “.. pada masa lalu pertunjukan Wayang Topeng bisa berlangsung sampai tiga hari tiga malam....Bahkan tidak mustahil jam 02.00 ada tamu yang datang....Nampak bahwa permainan Wayang Topeng disajikan berpanjang-panjang...”.Wido, dosen prodi Pendidikan Seni Tari dan Musik, Universitas Negeri Malang dalam wawancara tgl 18 Nopember 2013 mengatakan bahwa: “... panjang pendek atau penuh tidaknya penyajian lakon tergantung pada adanya pesanan penanggap....". sementara itu berdasarkan analisis dokumen yang ditulis oleh Murgiyanto dan Munardi (1980:25) menyatakan bahwa:'Beberapa adegan menarik misalnya lawakan Patrajaya, Lawakan Demang Mones, adegan-adegan perang, tarian Klana Sewandana dan tarian Klana Gunungsari ....disajikan berpanjangpanjang....Banyak terjadi perulangan ragam gerak tari maupun adegan...”.

Mencermati penjelasan tersebut dapat dikatakan bahwa struktur penyajian Wayang Topeng Kedungmonggo, tergantung pada untuk maksud apa pertunjukan tersebut diselenggarakan. Faktor inilah yang oleh Robby Hidajat (wawancara tanggal 26 Nopember 2013) dikatakan: “...penyajian Wayang Topeng Kedungmonggo memiliki perbedaan gaya, pola gerak, dan struktur...struktur repertoar Panji pada Wayang Topeng Kedungmonggo berbeda dengan struktur penyajian kelompok yang lain".

\section{Tata urutan penyajian lakon Rabine Panji dengan durasi tidak penuh}

Untuk memenuhi keinginan masyarakat, maka Handoyo pimpinan sanggar menyusun lakon Rabine Panji dalam durasi yang sangat pendek, "...kurang lebih berdurasi dua jam..., atau kita namakan penyajian tidak penuh..." (wawancara tanggal 23 Nopember 2013). Mengenai hal ini, Robby dosen Prodi Pendidikan Seni Tari dan Musik, Universitas Negeri Malang yang juga peneliti Wayang Topeng mengatakan (wawancara tgl 25 Nopember 2013) bahwa:

Lakon Rabine Panji merupakan lakon baku, artinya lakon lama yang terdapat di berbagai jenis perkumpulan yang ada di Malang. Masalah baku dan tidak adalah disebabkan oleh kebutuhan penyajian,. sehingga lakon itu dapat dipadatkan atau disingkat.

Dengan demikian kesimpulan sementara adalah: (1) Struktur penyajian Wayang Topeng di Kedungmonggo dibedakan menjadi penyajian penuh dan penyajian tidak penuh; (2) Penyajian penuh dilakukan dengan durasi semalam suntuk dari jam 21.00 sampai jam 05.00; (3) Penyajian tidak penuh dilakukan dengan durasi hanya dua jam; (4) Penuh atau tidaknya penyajian berdampak pada lengkap atau tidaknya adegan /jejer yang disajikan

\section{Tata urutan penyajian musik iringan tari pada lakon Rabine Panji baik durasi penuh maupun durasi tidak penuh/pendek}

\section{Bagian Awal}

Diawali gendhing Giro, berlaras slendro sanga atau bisa juga dengan gendhing berlaras pelog pathet barang yakni gendhing Eling-eling laras pelog. Adapun notasinya sebagai berikut:

$$
\text { Buka: } \quad 2765327(6)
$$


Suprihatin, Pratamawati, Wahyuningtyas, Hartono, Transkripsi Struktur Penyajian | 65

$\begin{array}{llll}6723 & 5327 & 6365 & 3732 \\ 5653 & 6532 & 7576 & 3276 \\ 5672 & 3276 & 2327 & 3276 \\ 2327 & 3276 & 3565 & 7627 \\ 7276 & 2726 & 2726 & 3567 \\ 2327 & 6532 & 5352 & 6356 \\ 7676 & 3567 & 2765 & 3276\end{array}$

Dilanjutkan dengan gendhing Krangean, laras pelog pathet barang $3232 \quad 5653 \quad 5353 \quad 5653$

$5672 \quad 3276 \quad 3565 \quad 3276$

35653276

Selanjutnya, iringan tari menyesuaikan dengan durasi pergelaran. Apabila durasi pergelaran pendek maka langsung jejer sabrang, namun apabila pergelaran berdurasi lama maka adegan dimulai dengan jejer Jawa. Berikut ini adalah iringan pergelaran wayang topeng yang berdurasi pendek:

Jejer sabrang

Gending Klapa Ndhek Besakalan Bapangan

$$
\begin{array}{lll}
.2 .2 & .2 .1 & .6 .5
\end{array}
$$

$\begin{array}{llll}.6 .6 & .6 .2 & .6 .5 & .2 .1\end{array}$

$\begin{array}{llll}.2 .1 & .2 .6 & .2 .1 & .6 .5\end{array}$

Dilanjutkan dengan:

$\begin{array}{llll}.1 .6 & .1 .2 & .1 .3 & .1 .5 \\ .1 .5 & .1 .2 & .1 .3 & .1 .6\end{array}$

Bila dilanjutkan dengan kiprahan Klana maka diiringi dengan gending Gagak setra laras selendo atau pelog 8 sebagai berikut:

$\begin{array}{lll}6561 & .3 .2 & .6 .5\end{array}$

$\begin{array}{llll}\ldots 6 & .2 .1 & \ldots 6 & \ldots .\end{array}$

$\begin{array}{llll}\ldots 6 & .3 .2 & \ldots 6 & .2 .1\end{array}$

$\begin{array}{llll}\ldots 6 & .3 .2 & \ldots 6 & .2 .1\end{array}$

$\begin{array}{llll}\ldots 5 & \ldots 3 & \ldots 6 & \ldots 5\end{array}$

Mlaku:

$\begin{array}{llll}.621 & .6 .5 & .632 & .6 .5\end{array}$

$\begin{array}{llll}.632 & .621 & .3 .2 & .6 .5\end{array}$

$\begin{array}{llll}2621 & 6365 & 2612 & 5421\end{array}$

$\begin{array}{llll}5612 & 5421 & 3632 & 6165\end{array}$

$\begin{array}{llll}.2 .1 & .2 .6 & .2 .1 & .6 .5\end{array}$ 
66 | BAHASA DAN SENI, Tahun 44, Nomor 1, Februari 2016

$$
\begin{array}{rrrr}
.4 .6 & .4 .2 & .5 .3 & .2 .1 \\
.5 .6 & .1 .2 & .5 .3 & .2 .1 \\
.3 .6 & .3 .2 & .6 .1 & .6 .5
\end{array}
$$

Ada kalanya untuk menaikkan dinamika ditambah dengan greget saut sendhon 8 jugag sebagai berikut:

$\begin{array}{llllllllll}6 & 6 & 6 & & & & & & & \\ \text { Ywa } & \text { na } & \text { swah } & & & & & & & \\ 1 & 2 & 2 & 2 & 3 & 5 & 23 & 21 & & \\ \text { Ka } & \text { jeng } & \text { nya } & \text { as } & \text { ma } & \text { ra } & \text { ja } & \text { ti } & & \\ 5 & 5 & 5 & 5 & 5 & 5 & 5 & 6 & 65 & 32 \\ \text { A } & \text { de } & \text { ging } & \text { ka } & \text { yu } & \text { ja } & \text { ti } & \text { khas } & \text { tu } & \text { ba } \\ 6 & 6 & 6 & 6 & \text { i } & 6 & \text { i6 } & 5 & & \\ \text { Pang } & \text { pa } & \text { pat } & \text { ka } & \text { li } & \text { ma } & \text { pan } & \text { cer } & & \\ \text { i } & \text { i } & 5 & \text { i2 } & 5 & 2 & 53 & 23 & 21 & 6 \\ \text { se } & \text { kar } & \text { I } & \text { ra } & \text { tan } & \text { ke } & \text { na } & \text { wi } & \text { ni } & \text { lang } \\ 2 & 2 & 2 & 2 & 3 & 5 & 23 & 21 & & \\ \text { A } & \text { woh } & \text { pu } & \text { tra } & \text { la } & \text { wan } & \text { pu } & \text { tri } & & \\ 6 & 6 & 6 & 6 & 6 & 12 & 61 & 65 & & \\ \text { Ble } & \text { ger } & \text { e } & \text { ja } & \text { gat } & \text { se } & \text { ja } & \text { ti } & & \\ 1 & & & & & & & & & \\ \text { O } & & & & & & & & & \end{array}$

Ketika pergelaran berdurasi lama maka adegan dimulai dengan jejer Jawa dengan iringan sebagai berikut:

Gendhing lambang slendro 8 atau pelog.

$\begin{array}{llll} & 5356 & .2 .1 & .6 .5 \\ . .23 & 5356 & .235 & 3235 \\ . .56 & 1216 & .532 & 5356 \\ .2 .2 & .2 .2 & .123 & 2121 \\ . .56 & 1616 & .532 & 3565\end{array}$

Narasi dhalang (janturan)

$2356 \quad 5253 \quad 6666 \quad 3332$

$666655536666 \quad 6665$

$2222 \quad 5553 \quad 2222 \quad 2221$

$66665553 \quad 6356 \quad 5235$ 
Adegan ini berkaitan dengan jejer ratu dengan iringan gendhing samirah laras slendro atau pelog sebagai berikut:

$$
\begin{array}{lll}
.653 & .6 .5 & .3 .2
\end{array}
$$

$\begin{array}{llll}.3 .2 & .1 .6 & .1 .6 & .5 .3\end{array}$

$\begin{array}{llll}.5 .3 . & .6 .5 & .6 .5 . & .3 .2\end{array}$

Rampogan wadya bala prajurit dipimpin sang patih diiringi gendhing sebagai berikut:

$3132 \quad 1516 \quad 1516 \quad 5253$

$5253 \quad 6365 \quad 6365 \quad 3132$

\section{$\underline{\text { Bagian Inti }}$}

Adegan pada bagian ini diiringi gending sampatan dengan laras pelog atau slendro. Gendhing ini juga berfungsi sebagai penyambung atau iringan pergantian adegan-adegan yang termasuk dalam adegan inti ini (dikenal dengan istilah mudhun jejer). Gendhing sampatan dimainkan dalam laras slendro 8 atau pelog pathet nem. Notasi gendhing ini adalah sebagai berikut:

$$
\text { 636. } 2323 \quad 5656
$$

$\begin{array}{llll}.5 .5 & .5 .5 & .3 .3 & .3 .3 \\ .5 .5 & .5 .5 & .1 .1 & .1 .1 \\ .1 .1 & .1 .1 & .6 .6 & .6 .6 \\ .2 .2 & .2 .2 & .5 .5 & .5 .5\end{array}$

Selanjutnya masuk ke adegan punakawan. Pada adegan ini diselipi iringan gadhingan:

$\begin{array}{llll}.6 .5 & .6 .5 & .6 .5 & .6 .5\end{array}$

Bisa juga diselingi dengan gendhing jula-juli laras pelog pathet 8 untuk mendukung suasana humor sebagai berikut:

$\begin{array}{llll}.2 .1 & .2 .6 & .2 .1 & .6 .5 \\ .6 .5 & .4 .5 & .6 .5 & .2 .1\end{array}$

Syairan saron:

$\begin{array}{llll}5151 & 5421 & 2626 & 2456 \\ 2626 & 2456 & 1515 & 1245 \\ 1515 & 1245 & 6262 & 6542 \\ 6262 & 6542 & 5151 & 5421\end{array}$

Dilanjutkan dengan greget saut 8 laras pelog:

$\begin{array}{lllllllll}2 & 1 & 2 & 2 & 2 & 2 & 2 & 2 & \\ \text { Pe } & \text { teng } & \text { dhe } & \text { dhet } & \text { le } & \text { li } & \text { me } & \text { ngan } & \\ 2 & 3 & 5 & 3 & 2 & 1 & 1 & 1 & 1 \\ \text { Jum } & \text { pul } & \text { gra } & \text { na } & \text { da } & \text { lan } & \text { ka } & \text { ek } & \text { si } \\ 3 & 3 & 3 & 3 & 2 & 2 & 2 & 2 & 2\end{array}$


$\mathbf{6 8}$ | BAHASA DAN SENI, Tahun 44, Nomor 1, Februari 2016

Be da la ya lam pah wa lu ya

$\begin{array}{lllllll}6 & 6 & 1 & 1 & 1 & 6 & 5\end{array}$

$\mathrm{Du}$ du pe te nge nya mun

$\begin{array}{lllllllll}2 & 2 & 1 & 5 & 5 & 5 & 5 & 3 & 2\end{array}$

$\mathrm{Pe}$ te nge ku kus e sen ja ta

$\begin{array}{lllllll}5 & 6 & 1 & 2 & 6 & \text { i6 } & 5\end{array}$

Cam pur ma rang pra ha ra

Adegan panji (kasatriyan) dengan iringan gendhing bedhat laras slendro manyura sebagai berikut:

$\begin{array}{llll}.521 & .516 & .521 & .2 .6 \\ .532 & .5 .3 & .521 & .3 .5\end{array}$

Lik:

$2321 \quad 3216 \quad 2321 \quad 5653$

$\begin{array}{llll}5612 & 1653 & 2321 & 3216\end{array}$

Selingan galo irig

12.. $1253 \quad 12 . . \quad 1216$

12.. $1253 \quad 1265 \quad 3653$

$\begin{array}{llll}.1 .6 & .1 .2 & .1 .6 & .5 .3\end{array}$

$\begin{array}{llll}.2 .3 & .2 .1 & .3 .2 & .1 .6\end{array}$

$\begin{array}{llll}.132 & 6123 & .1 .2 & .1 .6\end{array}$

$\begin{array}{llll}.3 .5 & .3 .2 & .5 .6 & .5 .3\end{array}$

$\begin{array}{llll}6523 & 6523 & .6 .5 & .2 .3\end{array}$

$\begin{array}{llll}.2 .3 & .2 .1 & .3 .2 & .1 .6\end{array}$

Sebagai iringan sela adegannya mempergunakan krucilan 8 laras pelog:

Dong deng

$2 . .1 \quad 6456 \quad 5321$

$.2 .1 \quad .2 .1 \quad 2212 \quad 3532$

$\begin{array}{llll}.3 .2 & .3 .2 & 3235 & 1235\end{array}$

$\begin{array}{llll}6.5 & .6 .5 & 6563 & 5216\end{array}$

$\begin{array}{llll}.1 .6 & .1 .6 & 2212 & 3532\end{array}$

$\begin{array}{llll}.3 .2 & .3 .2 & 1121 & 2321\end{array}$

$\begin{array}{llll}.2 .1 & .2 .1 & 2321 & 3532\end{array}$

$\begin{array}{llll}.3 .2 & .3 .2 & 3235 & 1235\end{array}$

$\begin{array}{llll}.6 .5 & .6 .5 & 2212 & 2532\end{array}$ 


$$
\begin{array}{llll}
.3 .2 & .3 .2 & 3235 & 1235 \\
.6 .5 & .6 .5 & 6365 & 5216 \\
.1 .6 & .1 .6 & 5321 & 2321 \\
\text { suwuk } & & 2123 & 2165
\end{array}
$$

Peralihan menuju adegan tengah malam dengan menggunakan sendhon pathet 9 sebagai berikut:

$\begin{array}{llllllllllll}3 & 56 & 5 & 6 & 653 & 2 & & & & & & \\ \text { E } & \text { byar } & \text { ra } & \text { na } & \text { ning } & \text { wang } & & & & & & \\ 6 & 6 & 1 & 23 & 6 & 6 & 6 & 6 & 6 & 65 & 3 & \\ \mathrm{~A} & \text { na } & \text { pa } & \text { dhang } & \text { du } & \text { du } & \text { pa } & \text { dha } & \text { nge } & \text { sur } & \text { ya } & \\ 1 & 1 & 1 & 123 & 1216 & 2163216532 & & & & & \\ \text { La } & \text { wan } & \text { kar } & \text { ti } & \text { ka } & \text { o } & & & & & & \\ 6 & 6 & 6 & 6 & 6 & 6 & 6 & 6 & 6 & & & \\ \mathrm{Se} & \text { ja } & \text { ti } & \text { ne } & \text { kang } & \text { a } & \text { ran } & \text { pa } & \text { dhang } & & \\ 3 & 2 & 1 & 1 & 1 & 1 & 65 & 32 & & & & \\ \text { Pa } & \text { dha } & \text { nge } & \text { cah } & \text { yo } & \text { kang } & \text { we } & \text { ning } & & & & \\ 1 & 2 & 3 & 3 & 3 & 3 & 3 & & & & & \\ \mathrm{Na} & \text { dyan } & \text { da } & \text { tan } & \text { am } & \text { bo } & \text { ga } & & & & & \\ 1 & 1 & 23 & 121 & 6 & & & & & & & \\ \text { Man } & \text { cur } & \text { man } & \text { co } & \text { rong } & & & & & & & \\ 3 & 3 & 3 & 3 & 3 & 3 & 3 & 3 & 36 & 5 & 32 & 1 \\ \text { Pa } & \text { dhang } & \text { o } & \text { ra } & \text { a } & \text { na } & \text { kang } & \text { nga } & \text { ling } & \text { a } & \text { ling } & \text { i } \\ 2 & 2 & 2 & 2 & 1 & 1 & 6 & 6 & 6 & 6 & 61 & 6 \\ \text { Ra } & \text { we } & \text { ra } & \text { we } & \text { ran } & \text { tas } & \text { ma } & \text { lang } & \text { ma } & \text { lang } & \text { si } & \text { mim } \\ 3 & & & & & & & & & & & \\ \text { Pal } & & & & & & & & & & & \end{array}$

Iringan antar adegan pada adegan tengah malam adalah krucilan 9 sebagai berikut: $5321 \quad 3532$
A. $\quad .3 .2 \quad .3 .2 \quad 5621 \quad 5653$
$\begin{array}{llll}.5 .3 & .5 .3 & 6532 & 3216\end{array}$
$\begin{array}{llll}.1 .6 & .1 .6 & 5421 & 2321\end{array}$
B. $\quad .2 .1 \quad .2 .1 \quad 2123 \quad 5653$
$\begin{array}{llll}.5 .3 & .5 .3 & 5612 & 3532\end{array}$
$\begin{array}{llll}.3 .2 & .3 .2 & 6523 & 5323\end{array}$
$\begin{array}{llll}.5 .3 & .5 .3 & 6356 & 5216\end{array}$ 


$$
\begin{array}{llll}
.1 .6 & .1 .6 & 5421 \quad 2321
\end{array}
$$

Ada kalanya bila dibutuhkan mempergunakan macapat sinom laras pelog nem sebagai berikut:

$\begin{array}{llllllll}2 & 3 & 5 & 5 & 5 & 5 & 5 & 5 \\ \text { Ka } & \text { yu } & \text { gung } & \text { ri } & \text { nek } & \text { sa } & \text { jal } & \text { ma } \\ 2 & 3 & 5 & 6 & 4 & 5 & 6 & 4546 \\ \text { Bi } & \text { bis } & \text { bang } & \text { so } & \text { beng } & \text { wa } & \text { na } & \text { dri } \\ 6 & 1 & 2 & 216123 & 6 & 6 & 5 & 31261 \\ \text { Nggo } & \text { lek } & \text { i } & \text { sing } & & \text { ka } & \text { ya } & \text { nga pa } \\ 3 & 5 & 6 & 5656 & 2 & 1 & 2 & 31216 \\ \text { Si } & \text { ra } & \text { nam } & \text { pik } & \text { mring } & \text { wak } & \text { ma } & \text { mi } \\ 3 & 5 & 6 & 1 & 1 & 1 & 3212 & 2 \\ \text { Ke } & \text { ma } & \text { ngi } & \text { ki } & \text { nar } & \text { ya } & \text { jam } & \text { pi } \\ & & & & & & & \\ 1 & 6 & 5 & 32 & 3 & 5 & 3 & 32356532 \\ \text { A } & \text { pes } & \text { te } & \text { men } & \text { ra } & \text { ga } & \text { ning } & \text { sun } \\ & & & & & & & \\ 6 & 5 & 1 & 6 & 5 & 3 & 3 & 3 \\ \text { Pen } & \text { ja } & \text { lin } & \text { gi } & \text { tik } & \text { ing } & \text { ku } & \text { da } \\ 3 & 3 & 1 & 23 & 2 & 1 & 6 & 6 \\ \text { Wus } & \text { ke } & \text { ba } & \text { cut } & \text { tres } & \text { na } & \text { ma } & \text { mi } \\ 3 & 5 & 46 & 56 & & & & \\ \text { Ken } & \text { thang } & \text { ram } & \text { bat } & & & & \\ 5 & 3 & 2 & 2 & 3 & 5 & 3 & 3 \\ \text { Wong a } & \text { yu } & \text { sun } & \text { le } & \text { la } & \text { le } & \text { la } \\ 2161212 & & & & & & \\ \text { La } & & & & & & & \end{array}$

Usai tembang ini dilanjutkan gending rengga sri laras pelog:

$\begin{array}{llll}3276 & 5653 & 2327 & 6532\end{array}$

$\begin{array}{llll}.672 & 3567 & 6535 & 6356\end{array}$

Gending pada menjelang akhir pertunjukan adalah gendhing krucilan 9 miring laras pelog:

$\begin{array}{llll}6 & .235 & 6532 & \\ .3 .2 & .3 .2 & 5653 & 2327 \\ .2 .7 & .2 .7 & 6532 & 5676 \\ .7 .6 & .7 .6 & 5323 & 5653 \\ .5 .3 & .5 .3 & 6532 & 3532\end{array}$

Apabila suwuk:

$$
2327 \quad 3276
$$

\section{$\underline{\text { Bagian Akhir }}$}

Gendhing penutup menggunakan gendhing krucil serang laras pelog, namun sebelumnya ada greget saut serang sebagai berikut:

$\begin{array}{llllllll}5 & 67 & 7 & 7 & 2 & 32 & 7 & 7 \\ \mathrm{Pi} & \text { tung } & \text { di } & \text { na } & \text { pi } & \text { tung } & \text { be } & \text { ngi }\end{array}$


Suprihatin, Pratamawati, Wahyuningtyas, Hartono, Transkripsi Struktur Penyajian | 71

Umpak:

$\begin{array}{llllllllll}5 & 5 & 5 & 5 & 5 & 5 & 5 & 5765 & 3 & \\ \mathrm{Tu} & \text { tuk } & \mathrm{I} & \text { ra } & \text { wong } & \text { ban } & \text { da } & \text { yu } & \text { da } & \\ 3 & 5 & 6 & 7 & 7 & 7 & 7 & 7 & & \\ \mathrm{Yu} & \mathrm{da} & \mathrm{yu} & \mathrm{da} & \text { ne } & \text { ma } & \text { ngla } & \text { wan } & & \\ 6 & 6 & 6 & 6 & 6 & 5 & 5 & 3 & 6 & 5 \\ \mathrm{Bu} & \text { rat } & \text { pi } & \text { na } & \text { dhang } & \text { su } & \text { ja } & \text { na } & \text { mu } & \text { rub }\end{array}$

$\begin{array}{llll}.7 .6 & .5 .3 & .2 .7 & .2 .3\end{array}$

Gendhing penutup pertunjukan adalah krucil serang laras pelog sebagai berikut:

$6 \ldots 3567 \quad 5676$

$\begin{array}{llll}.7 .6 & .7 .6 & 7567 & 5327\end{array}$

$\begin{array}{llll}.2 .7 & .2 .7 & 6365 & 6235\end{array}$

$\begin{array}{llll}.6 .5 & .6 .5 & 6356 & 7356\end{array}$

$.7 .6 \quad .7 .6 \quad 5253 \quad 5123$

Dilanjut:

$\begin{array}{llll}.5 .3 & .5 .3 & 6356 & 7356\end{array}$

$\begin{array}{llll}.7 .6 & .7 .6 & 7567 & 5327\end{array}$

$\begin{array}{llll}.2 .7 & .2 .7 & 6365 & 6235\end{array}$

$\begin{array}{llll}.6 .5 & .6 .5 & 6356 & 7356\end{array}$

$\begin{array}{llll}.7 .6 & .7 .6 & 5253 & 5123\end{array}$

Suwuk: $\quad .1 .2 \quad 3.35 \quad 3123$

Gendhing penutupnya adalah Krangean laras pelog pathet serang sebagai berikut:

$\begin{array}{llll}.2 .7 & .2 .7 & .5 .6 & \\ .7 .6 & .2 .7 & .2 .7 & .5 .6 \\ .7 .6 & .2 .7 & .2 .7 & .5 .6 \\ .3 .2 & .3 .5 & .3 .6 & .3 .2 \\ .6 .2 & .5 .3 & .5 .6 & .7 .6\end{array}$

\section{Pengembangan Teknik Gerak Lakon “Rabine Panji” Pada Sanggar Wayang Topeng Asmoro Bangun Dusun Kedungmonggo}

Menurut Soerjabrangtad (1981:2-5) tari Yogyakarta dan Surakarta memiliki konsep filsafat tari yang di namakan Joged Mataram terdiri dari empat aturan pokok: “...(1) nyawiji, greged ,sengguh , ora mingkuh; (2) Hasta Sawanda, yaitu delapan aturan yaitu: PPLWLUWIG, maksudnya Pacak, Pancat, Lutut, Wilet, Luwes,Ulat, Wirama, Gending. Hasil wawancara dengan Wido (tgl 19 Nopember 2013) dosen pada Prodi Pendidikan Seni Tari dan Musik Universitas Negeri Malang mengatakan bahwa: “... setiap tari tradisi mempunyai konsep gerak yang harus dijadikan sebagai pedoman dalam membawakan sebuah tarian...". Dari analisis dokumen yang ada pada Sanggar Asmoro Bangun Kedungmonggo, setiap penari harus memahami konsep teknik dasar menari yaitu: (1) Patrap; (2) Solah; (3) Greged; (4). Ulat. ; (5) Pandeleng. M. Sholeh Adi Pramono (wawancara, 20 November 2013), mengatakan bahwa, “.... Joged ngana dudu kumrembyahe asta dawane jangkah nanging ketarik sliro saka dayahe greged jero. Soerjodiningrat (1934: 3 ), tari adalah gerak seluruh anggota tubuh yang bersamaan dengan bunyi- bunyian musik, diatur dan selaras dengan irama lagu serta mendapat ekpresi sesuai dengan maksud dan tujuan tari tersebut sesuai dengan wiraga, wirama, dan wirasa. Wido Minarto (wawancara 
tanggal 20 Nopember 2013) mengatakan bahwa teknik gerak pada pertunjukan wayang topeng ada $5 \mathrm{M} /$ malima yaitu:

(1). Majeg (M1). Majeg maknanya kokoh dalam bahasa jawa di artikan jatuh, benar- benar siap, tidak ada sedikit keraguan di dalam melakukan gerak, baik kesiapan otot- otot fisik maupun kesiapan rohani berkaitan dengan penghayatan; (2) Mapak (M2). Secara fisik mapak adalah "Menghadap" atau ngadep, bukan pada posisi miring atau serong. Artinya ngadep adalah benar- benar berani (wani). Berani karena sudah memiliki kesiapan, kemantapan hati, tidak ada lagi rasa was- was atau keraguan; (3) Megeng (M3). Megeng yaitu mengendalikan. Dalam kaitanya dengan teknik gerak, megeng adalah kemampuan untuk mengendalikan diri, baik secara kontrol emosi, maupun Kontrol tenaga agar tidak berlebihan (over) atau sebaliknya terlalu lemah; (4). Mapan (M4). Yaitu menempati tempat yang semestinya dalam kondisi yang benar dan tepat, dan tidak ragu; (5) Mengku (M5). Mengku adalah menguasai dari segala aspek baik lahir maupun batin.

Kelima pedoman tersebut yang menjadi satukesatuan yang saling menunjang. Solah tidak akan bagus tanpa di landasi teknik yang benar, patrap dan solah akan mantap berisi jika di semangat dengan greged, greged akan sempurna jika penggunaan ulatnya tepat dan pandeleng yang benar. Di samping pedoman teknik tersebut, Wayang Topeng Malang memiliki pegangan panjeran yaitu: megeng, mengku, mengkal, mapan dan mapag. M. Sholeh Adi Pramono (wawancara, 20 November 2013)

Dari paparan data tersebut dapat disimpulkan sementara bahwa: (1) Setiap tari tradisi selalu punya acuan atau patokan yang harus dipahami dan diikuti oleh penari jika menginginkan dapat menari dengan benar sesuai teknik gerak tarian tersebut; (2) Tari tradisional kerakyatan tidak memiliki patokan yang baku seperti layaknya tari tradisional istana; (3) Ada teknik baku yang dikembangkan di Sanggar Asmoro Bangun tetapi sifatnya umum sebagaimana teknik gerak tari yang meliputi unsur gerak kepala, tangan, badan dan torso; (4) Lima pedoman teknik menari pada pertunjukan Wayang Topeng Malang tersebut luluh menjadi satu kesatuan yang saling menunjang; (6) Solah tidak akan bagus tanpa di landasi patrap yang benar, patrap dan solah akan manteb jika berisi dengan spirit dengan greged; (6) Greged akan sempurna jika penggunaan tepat dan dengan pandeleng benar.

\section{SIMPULAN DAN SARAN}

Struktur penyajian Lakon Rabine Panji mengikuti pola struktur pembuka, gendhing Giro dilanjutkan tari Topeng Patih, inti adalah penyajian lakon Rabine Panji. Jika penyajian penuh maka pagelaran dimulai dari: Jejer 1 (kerajaan jenggolo)/Jowo); Jejer 2 ( kerajaan sabrang); Perang gagal; Kaputren,Sigek / jeda, ( bapang); Jejer Kediri, Kahyangan, Alas 1, Alas 2, Alun2 Kediri, penyajian tidak penuh langsung: Jejer 2, kerajaan sabrang; Jejer Kediri; Kaputren; Kahyangan; Alas 1; Alas 2; Alun2. Tata urutan gendhing yang dipergunakan untuk mengiringi lakon tidak sama antara penyajian durasi penuh dan durasi tidak penuh.dan penutup lakon berupa alunan gendhing.

Pengembangan teknik gerak lakon Rabine Panji tetap berpedoman pada pedoman umum teknik gerak tari Malang yaitu 5M (megeg, mapak, megeng, mapan, dan mengku) serta konsep teknik gerak patrap, solah, greged, ulat, dan pandeleng. Dapat dicermati bahwa unsur gerak yang baku dalam pertunjukan Wayang Topeng Malang baik gaya putra maupun putri memiliki susunan sebagai berikut: gerak pokok $\rightarrow$ gejug gawang $\rightarrow$ singget solah $\rightarrow$ singget $\rightarrow$ mundur gawang. 
Disarankan untuk: (1) Mahasiswa Prodi Pendidikan Seni Tari dan Musik Universitas Negeri Malang agar dapat melakukan penelitian sejenis terhadap berbagai lakon yang dimainkan dalam seni tradisional Wayang Topeng Malang di sanggar yang lain sehingga hasil penelitian dapat dipergunakan sebagai dokumentasi terhadap kesenian khas Malang sekaligus mengupayakan pelestarian agar terjaga dari kepunahan karena tidak adanya dokumen tertulis; (2) Untuk Universitas Negeri Malang khususnya Fakultas Sastra agar dapatnya memberikan ruang berupa dukungan sumber daya manusia ataupun sumber daya sarana prasarana untuk dapatnya seni tradisi Wayang Topeng Malang lebih dikenal oleh masyarakat Indonesia khususnya dan masyarakat Internasional umumnya dalam bentuk dukungan dana, kesempatan promosi dan lain sebagainya; (3) Bagi Pemerintah Daerah Kabupaten Malang dan pengembang seni tradisi agar dapatnya meningkatkan potensi seni tradisi Wayang Topeng Malang sebagai komoditas pariwisata berbasis pariwisata budaya dan atau alternatif pengembangan desa wisata, di wilayah di mana sanggar Wayang Topeng berada. Dengan adanya campur tangan pemerintah dan pengembang tersebut maka kehidupan seniman tradisi akan meningkat secara ekonomi, untuk dipergunakan memenuhi hajat hidupnya. Jika hajat hidup terpenuhi maka kesetiaan dan kecintaan terhadap seni tradisional akan terjaga.

\section{DAFTAR RUJUKAN}

Bastomi, S. Apresiasi Kesenian Tradisional. Semarang: IKIP Semarang.

Burns, R. B. 1994. Introduction to Rresearch Methods.2rd. Ed. Melbourne: Longman Cheshire Pty.Limited.

Erneste, P . 1983. Rendra Mempertimbangkan Tradisi. Jakarta: PT Gramedia.

Hidajat, R. 1996. Topeng Bapang. Lemlit UM. penelitian tidak diterbitkan.

Hidajat, R. 2000. Makna 4 Tokoh Sentral Wayang Topeng Malang. Malang: UM. Penelitian tidak diterbitkan.

Hidajat, R. 2005. Wayang Topeng Malang: Kajian Struktur Simbolik. Malang:UM. Penelitian tidak diterbitkan.

Munardi, M.1980. Topeng Malang: Pertunjukan Dramatari Tradisional Di Daerah Kabupaten Malang. Jakarta: Proyek Sasana Budaya. Direktorat Jenderal Kebudayaan Departeman Pendidikan Dan Kebudayaan.

Pramono, A., Sholeh. M, Supriyanto. H. 1997. Drama Tari Wayang Topeng Malang. Malang: Padepokan Seni Mangun Dharmo Tumpang.

Septivirawan, A. 2011. Tari Topeng Malangan Yang Nyaris Punah, (Online), (http://www.kompasiana.com/ anies_septivirawan/tari-topeng-malangan-yang-nyarispunah_5510d5d3813311d434bc7094), diakses 28 oktober 2011.

Soedarsono, R. B. 1999. Metodologi Penelitian Seni Pertunjukan Dan Seni Rupa. Yogyakarta: MSPI.

Sutopo, H. B. 2002. Metodologi Penelitian Kualitatif. Surakarta: Sebelas Maret University Pres.

Yudistira, W. 2010. Yuk Kita Cintai Budaya Kita. (online), (http://widyasite.blogspot.com). diakses 23 Januari 2010.

Yuwana, S. S. 2001. Metode Penelitian Kebudayaan. Surabaya: Unesa Unipress Bekerjasama dengan Citra Wacana.

Zuhri, S. 2009. (Online), (http://www. jelajahbudaya. com/kabar-budaya/senyum-topengyang-kini-menangis.html). diakses tanggal 12 mei 2009. 